\title{
CHEMOMETRIC CHARACTERIZATION OF TEXTILE WASTE WATERS FROM DIFFERENT PROCESSES
}

\author{
TINA JERIČ ${ }^{1}$, ALENKA MAJCEN LE MARECHAL ${ }^{1}$, \\ DARJA KAVŠEK ${ }^{2}$, DARINKA BRODNJAK VONČINA ${ }^{3}$ \\ ${ }^{1}$ Faculty of Mechanical Engineering, University of Maribor, Smetanova 17, \\ 2000 Maribor, Slovenia \\ ${ }^{2}$ Regional Technological Centre Zasavje, Chemical-Technological Laboratory, \\ Nasipi 48, 1420 Trbovlje, Slovenia \\ ${ }^{3}$ Faculty of Chemistry and Chemical Engineering, University of Maribor, \\ Smetanova 17, 2000 Maribor, Slovenia
}

\begin{abstract}
The aim of this work is focused on water quality classification of the textile waste water streams and evaluation of pollution. Data from the chemical characterization of the effluents were elaborated to identify a useful separation in potentially treatment for reuse. This was done with the aim of realizing a full scale characterization of effluents. In the two textile companies analyzed, machineries are used to carry out different production processes such as sizing and desizing, weaving, scouring, bleaching, mercerizing, carbonizing, fulling, dying and finishing. Different process effluents from the same machinery were found to be very diverse in pollution level. 25 and 49 samples of textile waste waters from two different textile companies were analysed and physical chemical measurements were performed. The following physicochemical and chemical water quality parameters were controlled: absorbance measured at three different wavelengths, $\mathrm{pH}$, conductivity, turbidity, total suspended solids, volatile suspended solids, chemical oxygen demand, metals content ( $\mathrm{Ba}, \mathrm{Ca}, \mathrm{Cu}, \mathrm{Mn}, \mathrm{K}, \mathrm{Sr}, \mathrm{Fe}, \mathrm{Al}, \mathrm{Na}$ ) and total nitrogen content. For handling the results, basic statistical methods for the determination of mean and median values, standard deviations, minimal and maximal values of measured parameters and their mutual correlation coefficients, were performed. Different chemometric methods, namely, principal component analysis (PCA), cluster analysis (CA), and linear discriminant analysis (LDA) were used to find hidden information about textile waste water quality.
\end{abstract}

Key words: textile waste waters, water quality, chemometrics, principal component analysis, classification

\section{Introduction}

The chemical and physicochemical studies on textile waste water streams from two textile companies were performed in the time period 2008-2009. The quality of the textile waste water streams was followed and the classification has been made according to different textile process outlets. The classification is based on 19 chemical and physicochemical parameters. The aim of this work is to find the correlation between different textile process outlets and the variables obtained by physicochemical and chemical measurements, which can be used to construct a fast decision model for separating different textile waste water quality outlets.

Chemometric methods have been often used for the classification and comparison of different water samples (MASSART et al., 1997). Some examples of chemometric characterizations of waste water and pollution of water are described, for instance, in the case of chemi-thermo-mechanical pulp mill (TØNNING et al., 2005), micro- 
electronics industry (VELINOVA and KOUMANOVA, 1995), and in the case of waste waters in the Lagoon of Venice (CARRER and LEARDI, 2006). Chemometric methods have been used also for surface water quality and pollution estimation (ASTEL et al., 2008; KOWALKOWSKI et al., 2006; ASTEL et al., 2007), for characterization of water springs (RAGNO et al., 2007), for natural mineral waters (SARBU and ZWANZIGER, 2001; SILVA et al., 2002), for classification of ground waters (PANERO and DA SILVA, 2008), and for the oceanographic characterization of water (FERREIRA et al., 1999).

The quality of the textile waste water streams was studied through the years 2008 and 2009. The monitoring programme was performed on different textile process waste water effluents (outlets) from two textile companies. Textile waste water effluents were gathered from different textile processes (printing, finishing, dyeing, bleaching, washing, rinsing, mercerizing, softening and desizing) and from different machinery. Altogether 19 characteristic features were measured for 25 and 49 samples of textile waste waters from two textile companies, respectively. Water samples were collected and analysed during two years. Several chemometric methods were applied in order to visualize multivariate data and to enable a quick classification of samples, regarding to textile process waste water effluents (outlets).

\section{Materials and methods}

A standard method was used for sampling (ISO 5667-01: 1996 (E)). Textile waste water samples were collected in polyethylene bottles at the outlet. Standard analytical methods were used for the determination of 19 chemical and physicochemical variables. All reagents were analytical grade. The milli-Q system was used for purifying the water.

25 and 49 samples of textile waste water from two textile companies respectively, are characterized by 19 chemical and physicochemical variables: (1) $\mathrm{Ba},(2) \mathrm{Cu},(3)$ Mn, (4) K, (5) Sr, (6) Fe, (7) $\mathrm{Al}$, (8) Na, (9) Ca, (10) total nitrogen, (11) pH, (12) conductivity, (13) turbidity, (14) chemical oxygen demand, (15) total suspended solids, (16) volatile suspended solids, (17) absorbance at $436 \mathrm{~nm},(18)$ absorbance at $525 \mathrm{~nm}$, and (19) absorbance at $620 \mathrm{~nm}$. The results of all measurements have been investigated by different chemometric methods (MASSART et al., 1997): the basic statistical methods for the determination of mean and median values, standard deviations, minimal and maximal values of measured variables and their mutual coefficients. The Principal Component Analysis (PCA) (MASSART et al., 1997; TEACH/ME DATALAB 2.002, 1999) was applied for grouping of textile waste water samples due to measured variables. All the calculations and plots in the following (PCA) section were done with the Teach/Me software (TEACH/ME DATALAB $2.002,1999)$ using Teach/Me Data Analysis option.

\section{Results and discussion}

\subsection{Statistical screening of data}

The mutual correlation was sought for all measured variables. The maximal correlation coefficient for the data of 25 waste water samples from the first textile 
company was found between measurements of absorbance at $620 \mathrm{~nm}$ and copper $(\mathrm{r}=$ $0.99)$, between absorbance at $620 \mathrm{~nm}$ and absorbance at $525 \mathrm{~nm}(\mathrm{r}=0.99)$, between absorbance at $525 \mathrm{~nm}$ and copper $(\mathrm{r}=0.98)$, between total suspended solids and volatile suspended solids $(\mathrm{r}=0.98)$, between absorbance at $620 \mathrm{~nm}$ and potassium $(\mathrm{r}=$ $0.97)$, and between absorbance at $525 \mathrm{~nm}$ and potassium $(\mathrm{r}=0.96)$.

The maximal correlation coefficient for the data of 49 waste water samples from second textile company was found between measurements of absorbance at $525 \mathrm{~nm}$ and absorbance at $436 \mathrm{~nm}(\mathrm{r}=0.99)$, between measurements of sodium content and electrical conductivity $(\mathrm{r}=0.98)$, between total suspended solids and volatile suspended solids $(r=0.98)$, between potassium and manganese $(r=0.90)$, between absorbance at $620 \mathrm{~nm}$ and calcium $(\mathrm{r}=0.86)$, and between absorbance at $436 \mathrm{~nm}$ and sodium $(r=0.86)$.

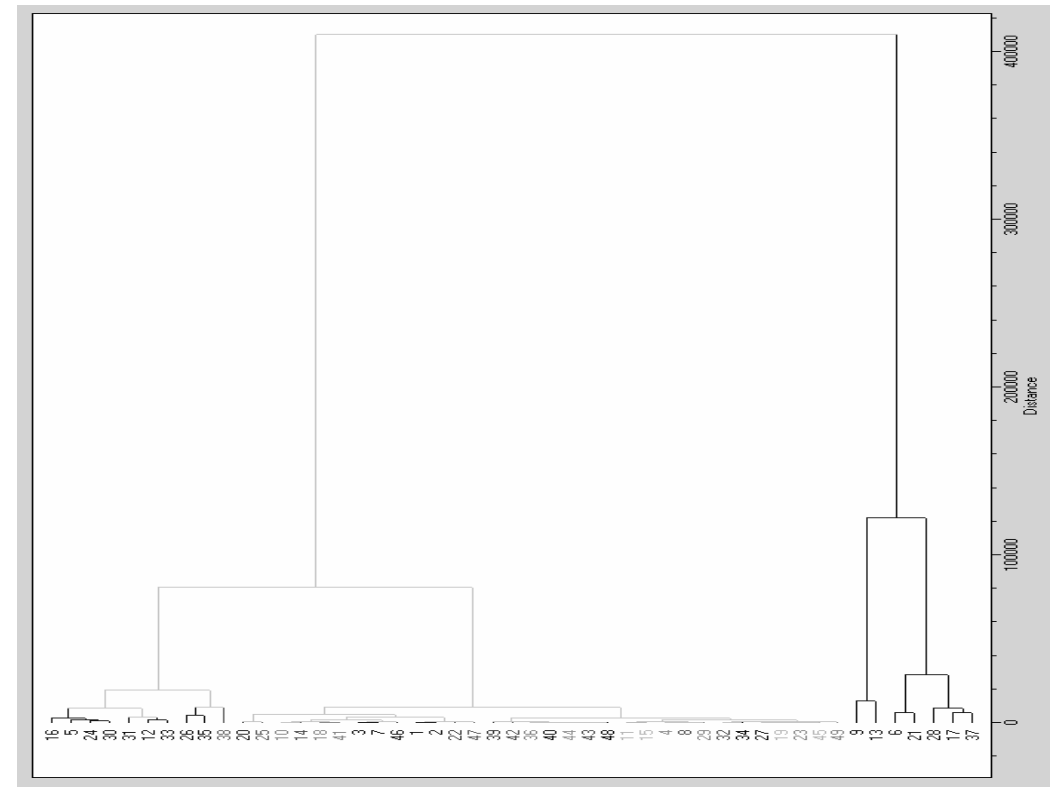

Fig. 1. Dendrogram of 49 textile waste water samples from the second textile company. Different shades correspond to 9 different textile process waste water outlets (classes).

Cluster analysis resulted in dendrogram shown in Fig. 1, where 49 textile waste water samples are divided into number of clusters, depending on the level of similarity based on Ward distance. First group of textile waste water samples (the right-most cluster) is quite well distinguished from others. This was also the most polluted water stream, as it was first outlet after dyeing process.

\subsection{Principal Component Analysis (PCA)}

PCA was performed to find the correlation of 25 or 49 textile waste water samples from two different textile companies, respectively, described with physicochemical 
and chemical variables (Fig. 2). Quality of textile waste waters depends on different textile processes and different waste water outlets. First outlet is always the most polluted one, as it belongs to the dyeing process. All other outlets are less polluted as they belong to rinsing processes. PCA was applied on the matrix composed of $25 \times 19$ and $49 \times 19$ elements. 25 or 49 rows represent textile waste water samples from two textile companies, respectively, composed of 19 variables. "Column centering" of the data was used, which means that the mean value of each column was subtracted from individual ( 25 or 49$)$ elements.
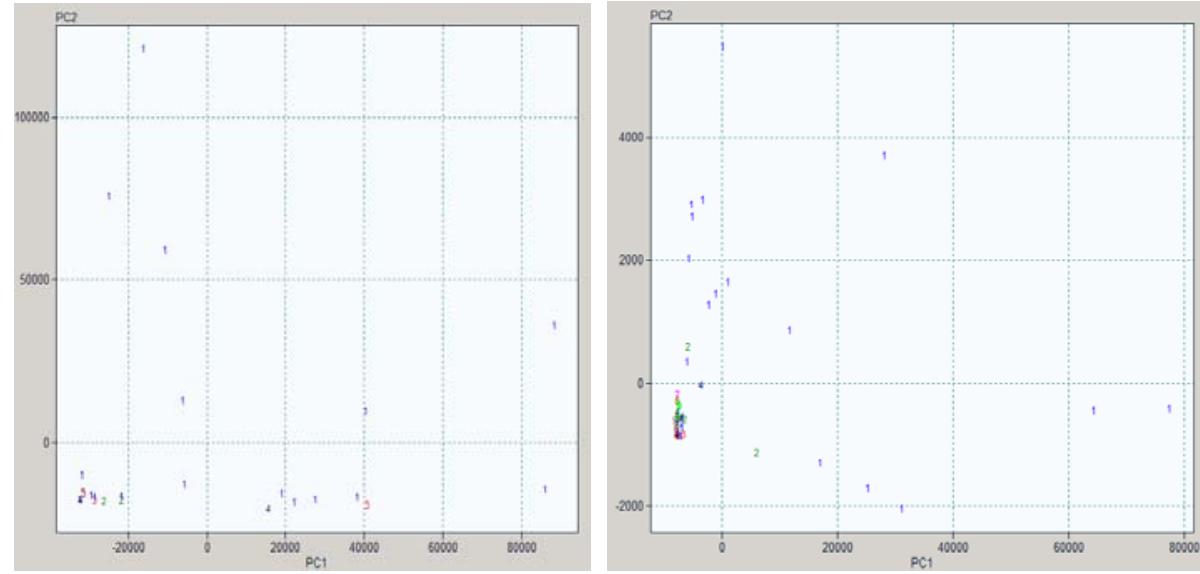

Fig. 2. PCA for 25 textile waste water samples from five different textile process waste water outlets denoted by class numbers from 1 to 5 and for 49 textile waste water samples from nine different textile process waste water outlets denoted by class numbers from 1 to 9 .
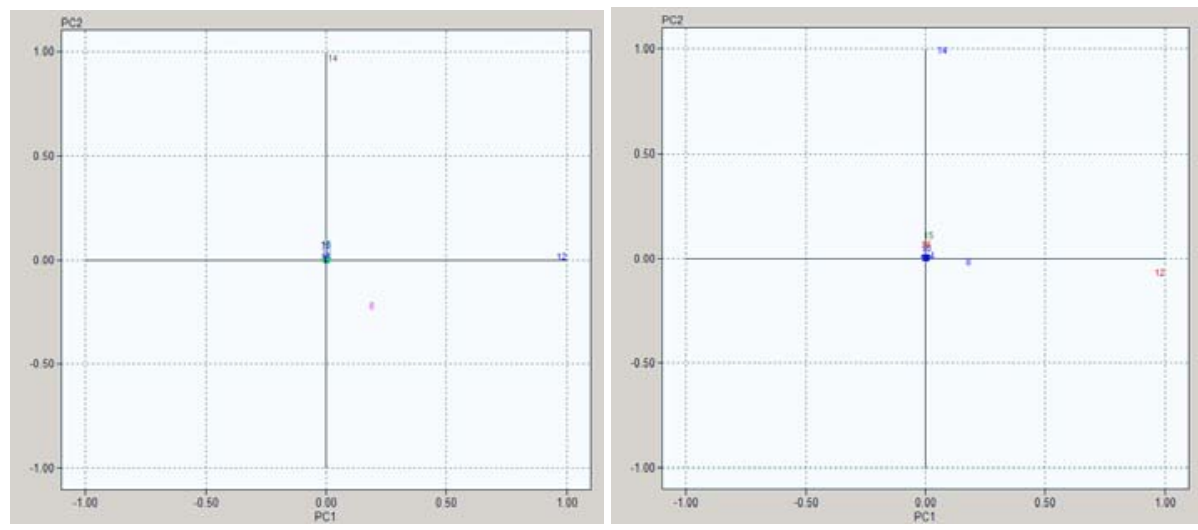

Fig. 3. PCA for textile waste water samples from nine and five different textile process waste water outlets; the loadings in $19 \mathrm{PC}$ axes are shown.

The PCA of the textile waste water samples represented with 19 variables is shown in Fig. 3. It can be seen that the first component, PC1, is associated with a group of variables such as conductivity and concentration of sodium, describing inorganic 
pollution, while the second component PC2 represents mainly the dependence on chemical oxygen demand, which is responsible for organic pollution.

\subsection{Linear discriminant analysis (LDA)}

LDA is a supervised learning method, which can determine the classification into predetermined classes. From Figures $4 \mathrm{a}$ and $4 \mathrm{~b}$ it can be seen that first class (first outlet from dyeing) for samples from both textile companies is well distinguished from all other outlets, belonging to rinsing processes.

\section{Plot of Discriminant Functions}

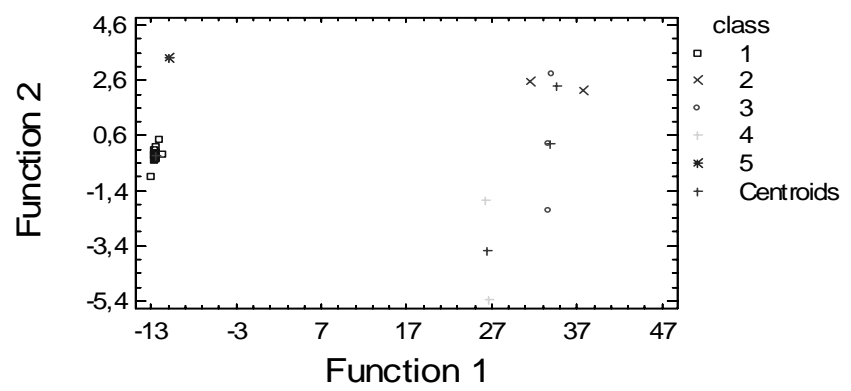

Fig. 4a. Linear discriminant analysis for 25 samples.

Plot of Discriminant Functions

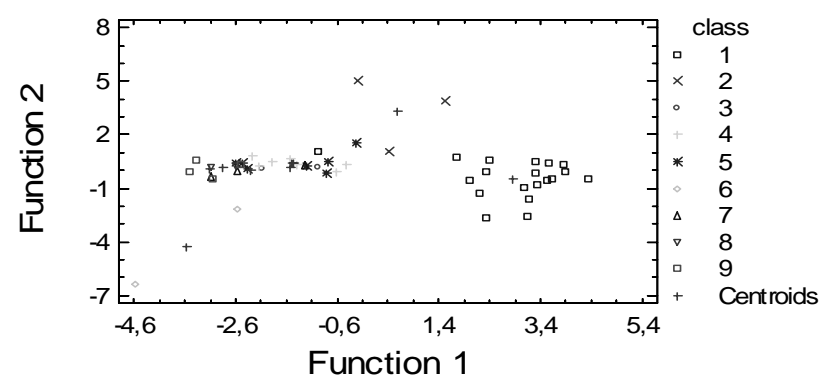

Fig. 4b. Linear discriminant analysis for 49 samples.

\section{Conclusions}

The aim of this work is to find the best solution for both textile companies for reuse of waste waters. For water recycling it is necessary to find correlation between different textile waste water streams. Chemometric methods can help in characterization of textile waste water effluents and thus can be used for separation of concentrated textile waste water streams from non concentrated ones. After collecting concentrated textile waste waters, evapoconcentration treatment process will be used before additional cleaning at waste water treatment plant. For treatment of non concentrated textile waste water streams AOP processes, like $\mathrm{H}_{2} \mathrm{O}_{2} / \mathrm{UV}$ process, and 
membrane filtration processes will be used. The cleaned waste water with the best quality can then be reused in different textile production processes.

\section{References}

ASTEL, A., TSAKOVSKI, S., BARBIERI, P., SIMEONOV, V.: Comparison of selforganizing maps classification approach with cluster and principal components analysis for large environmental data sets. Water Res., 41, 2007, 4566-4578.

ASTEL, A., TSAKOVSKI, S., SIMEONOV, V., REISENHOFER, E., PISELLI, S., BARBIERI, P.: Multivariate classification and modeling in surface water pollution estimation. Anal. Bioanal. Chem., 390, 2008, 1283-1292.

CARRER, S., LEARDI, R.: Characterizing the pollution produced by an industrial area: Chemometric methods applied to the Lagoon of Venice. Sci. Total Environ., 370, 2006, 99-116.

FERREIRA, M.M.C., FARIA, C.G., PAES, E.T.: Oceanographic characterization of northern Sao Paulo Coast: a chemometric study. Chemometr. Intell. Lab. Syst., 47, 1999, 289-297.

KOWALKOWSKI, T., ZBYTNIEWSKI, R., SZPEJNA, J., BUSZEWSKI, B.: Application of chemometrics in river water classification. Water Res., 40, 2006, 744-752.

MASSART, D.L., VANDEGINSTE, B.G.M., BUYDENS, L.M.C., De JONG, S., LEWI, P.J., VERBEKE, J.S.: Handbook of chemometrics and qualimetrics: Part A, Elsevier, Amsterdam, 1997.

PANERO, F.S., DA SILVA, H.E.B.: Application of exploratory data analysis for the characterization of tubular wells of the North of Brazil. Microchem. J., 88, 2008, 194-200.

RAGNO, G., DE LUCA, M., IOELE, G.: An application of cluster analysis and multivariate classification methods to spring water monitoring data. Microchem. J., 87, 2007, 119-127.

SARBU, C., ZWANZIGER, H.W.: Fuzzy classification and comparison of some Romanian and German mineral waters. Anal. Lett., 34, 2001, 1541-1552.

SILVA, F.V., KAMOGAWA, M.Y., FERREIRA, M.M.C., NOBREGA, J.A., NOGUEIRA, A.R.A.: Geographical discrimination of mineral waters from São Paulo state through exploratory analysis. Ecletica Quim, 27, 2002, 91-102.

TEACH/ME, SDL - SOFTWARE DEVELOPMENT LOHNINGER; TEACH/ME DATALAB 2.002, 1999, Springer, Berlin, Developed by H. Lohninger and the Teach/Me people.

TØNNING, E., SAPELNIKOVA, S., CHRISTENSEN, J., CARLSSON, C., WINTHER-NIELSEN, M., DOCK, E., SOLNA, R., SKLADEL, P., NØRGAARD, L., RUZGAS, T., EMNÉUS, J.: Chemometric exploration of an amperometric biosensor array for fast determination of wastewater quality. Biosens. Bioelectron., 21, 2005, 608-617.

VELINOVA, R.R., KOUMANOVA, B.K.: Statistical modelling of wastewater quality: The case of micro-electronics industry. Water Res., 29, 1995, 2541-2547.

WATER QUALITY-SAMPLING- PART 10: Guidance on sampling of waste water ISO 5667-01: 1996 (E). 